\title{
Intermodal Nonlinear Effects between Full Vectorial Modes in Few Moded Fiber
}

\author{
Rishøj, Lars Søgaard; Rottwitt, Karsten
}

Published in:

OSA Technical Digest

Link to article, DOI:

10.1364/NLO.2013.NM2B.3

Publication date:

2013

Document Version

Publisher's PDF, also known as Version of record

Link back to DTU Orbit

Citation (APA):

Rishøj, L. S., \& Rottwitt, K. (2013). Intermodal Nonlinear Effects between Full Vectorial Modes in Few Moded Fiber. In OSA Technical Digest (pp. NM2B.3). Technical University of Denmark.

https://doi.org/10.1364/NLO.2013.NM2B.3

\section{General rights}

Copyright and moral rights for the publications made accessible in the public portal are retained by the authors and/or other copyright owners and it is a condition of accessing publications that users recognise and abide by the legal requirements associated with these rights.

- Users may download and print one copy of any publication from the public portal for the purpose of private study or research.

- You may not further distribute the material or use it for any profit-making activity or commercial gain

- You may freely distribute the URL identifying the publication in the public portal 


\title{
Intermodal Nonlinear Effects between Full Vectorial Modes in Few Moded Fiber
}

\author{
Lars Rishøj* and Karsten Rottwitt \\ Technical University of Denmark, Ørsteds plads 343, 2800 Kgs. Lyngby, Denmark \\ ${ }^{*}$ Corresponding author: lris@fotonik.dtu.dk
}

\begin{abstract}
We experimentally investigate intermodal nonlinear mixing, such as Raman and four wave mixing. This is obtained by pumping in the fundamental mode, or either of the two full vectorial modes, $\mathrm{TM}_{01}$ and $\mathrm{TE}_{01}$ in a specialty designed few moded fiber.
\end{abstract}

(C) 2013 Optical Society of America

OCIS codes: 190.4370 (Nonlinear optics, fibers); 190.5650 (Raman effect); 190.4223 (Nonlinear wave mixing)

In past years intermodal Raman scattering has received increasing attention. Recently, the interaction between linear polarized psedomodes in a hollow-core photonic crystal fiber (PCF) was studied in [1]. Previously, spontaneous Raman scattering was utilized in the fiber used in this paper to generate vortex beams over a broad wavelength range by pumping at $1064 \mathrm{~nm}$ [2]. Furthermore, spacial division multiplexing (SDM) has been proposed as a mean to expand the optical communication bandwidth, either using multi-core fibers (MCFs) or few-moded fibers (FMFs). For long-haul communication optical amplification is crucial, in this regard FMFs has the advantage of intensity overlap between the different modes, which enables sharing of a single pump between multiple signal modes [3]. In this paper, measurements on intermodal nonlinear mixing is presented for a specialty designed fiber [4]. The pump is either in the fundamental mode, $\mathrm{HE}_{11}$, or one of the two full vectorial modes, $\mathrm{TM}_{01}$ or $\mathrm{TE}_{01}$, whereas the signal is always in $\mathrm{HE}_{11}$.

The schematics of the experimental setup is provided in Fig. 1a. The pump source is a Q-swithed Nd:YAG laser

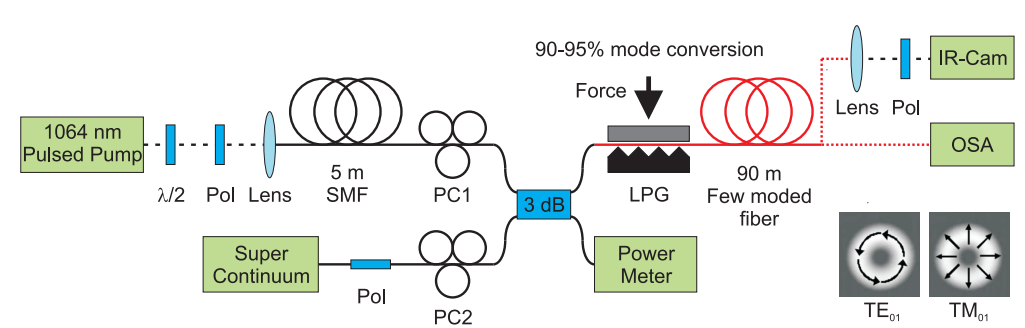

(a)

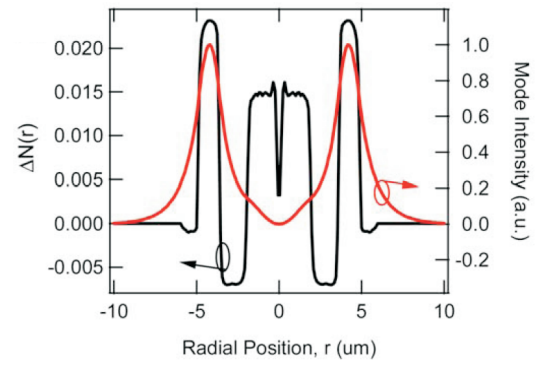

(b)

Fig. 1: (a) Schematics of the experimental setup. (b) Refractive index profile (black) similar to FMF, and the radial intensity profile for TE 01 (red) [4].

producing $700 \mathrm{ps}$ pulses, with a peak power of $21 \mathrm{~kW}$, and a repetition rate of $6 \mathrm{kHz}$. The pump laser is coupled into $5 \mathrm{~m}$ of single moded fiber (SMF), in which the seed signal is generated via spontaneous Raman scattering (SRS). The mode excitation is performed in the few moded fiber (FMF) using a long period microbend grating (LPG). The grating is created by pressing an aluminium block with periodic grooves and a rubber pad together. Insets are provided of the two modes of interest; the arrows indicate the polarization of the mode. The supercontinuum source is only used when tuning the resonance wavelength of the grating; this is done by rotating the grating block. The mode coupling is maximized by adjusting the polarization controller $(\mathrm{PC} 1)$ and the pressure applied to the grating. Typical conversion efficiencies between the fundamental mode and either of the higher order modes (HOMs) are approximately 90-95\%. The output of the FMF is either measured with an OSA or imaged on a camera. The refractive index profile of the FMF is shown in Fig. 1b. The fiber design eliminates the degeneracy of the first mode group consisting of $\mathrm{TM}_{01}$ (radially polarized), $\mathrm{TE}_{01}$ (azimuthally polarized), and the two degenerated modes $\mathrm{HE}_{21}$ (mixed polarized). Therefore, strong mode coupling within the first mode group yielding the familiar $\mathrm{LP}_{11}$ modes is avoided, and controlled excitation of the individual full vectorial modes is ensured, together with stable propagation along the fiber [4].

The Raman gain at a signal wavelength of $1117 \mathrm{~nm}$ as a function of peak power of the pump is shown in Fig. 2a. The signal is always in the fundamental mode, $\mathrm{HE}_{11}$, whereas the pump is in either $\mathrm{HE}_{11}, \mathrm{TM}_{01}$, or $\mathrm{TE}_{01}$ as indicated by 
the legend. The Raman gain is found based on spectral measurements of the average power immediately after the LPG and after approximately $90 \mathrm{~m}$ of FMF. Theoretically, straight lines are expected as pump depletion is not occurring. Deviations are observed at low gain since the spectra are close to the noise floor of the OSA, and at high gain since the OSA is approaching saturation. Experimentally it is observed that the Raman gain is higher when pumping in the HOMs. The process of Raman scattering depends primarily on the co-polarized intensity overlap integral between the interacting modes. However, even though this overlap integral is smaller when the pump is in the $\mathrm{TM}_{01}$ and $\mathrm{TE}_{01}$ modes, these modes have the unique feature of being inherently polarization preserving [4]. Hence, the strength of Raman scattering becomes independent of polarization walk-off, which is known to reduce the gain by a factor of two when both pump and signal are in the fundamental mode. It is further speculated that the high gain obtained when pumping in the HOMs is related to the large germanium concentration in the outer ring of the refractive index profile, see Fig. 1b, as this is known to increase Raman scattering [5]. Spectra after 90 m of propagation in the FMF,

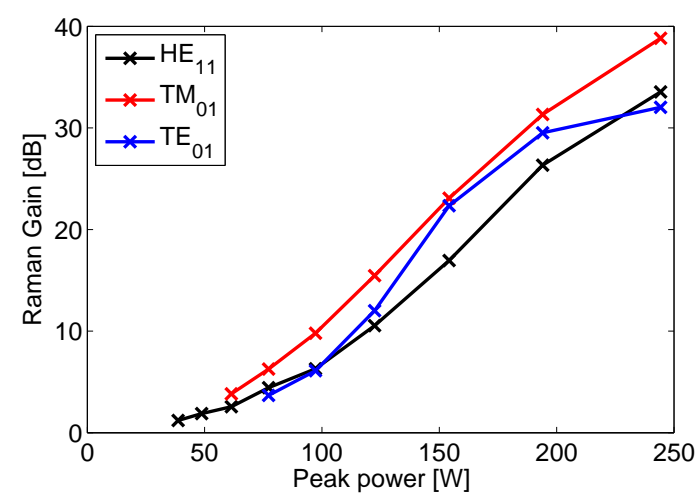

(a)

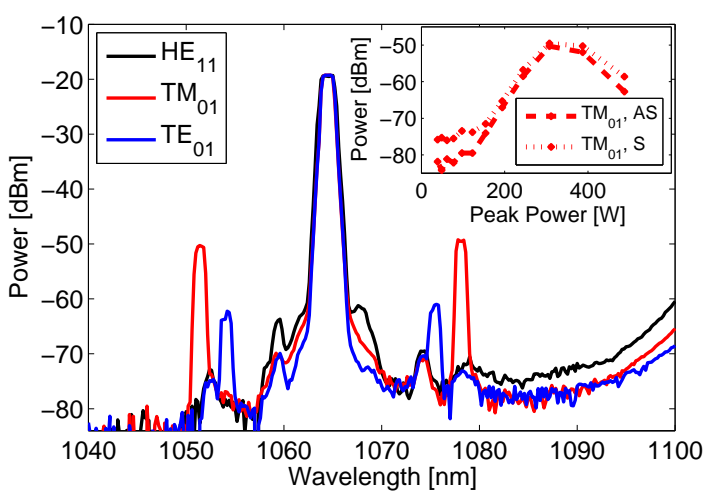

(b)

Fig. 2: (a) Raman gain through $90 \mathrm{~m}$ fiber, at a signal wavelength of $1117 \mathrm{~nm}$. The pump mode is indicated by the legend. (b) Spectra after $90 \mathrm{~m}$ of propagation and $300 \mathrm{~W}$ of peak power, the pump mode is indicated by the legend. The pump is saturating the OSA for all measurements.

with pump peak power of $307 \mathrm{~W}$ are shown in Fig. $2 \mathrm{~b}$, the mode of the pump is indicated by the legend. The peaks occurring symmetrically around the pump when pumping in either of the two HOMs are contributed to four wave mixing (FWM). The two HOMs have slightly different propagation constants, which leads to the few nanometer shift of the peak, i.e. the narrow phase matched wavelength region. The inset shows the power of the stokes (S) and antistokes (AS) when the pump is in the $\mathrm{TM}_{01}$ mode as a function of pump peak power. The decrease in FWM power for larger pump powers is expected to be caused by depletion of the pump, which sets in as several cascaded SRS processes starts to take place.

In summary, intermodal Raman gain was measured in a specialty designed fiber when pumping in the full vectorial modes, $\mathrm{TM}_{01}$ or $\mathrm{TE}_{01}$. Over $30 \mathrm{~dB}$ of Raman gain was obtained using $90 \mathrm{~m}$ of FMF and pump peak powers of $250 \mathrm{~W}$. Furthermore, when pumping in the HOMs FWM processes was also observed at wavelengths close to the pump.

\section{Acknowledgment}

The Danish Research Council for Technology and Production Sciences (project 09-066562) is acknowledged for financial support. Prof. Siddharth Ramachandran for helping with the setup and general fruitful discussions. OFS Fitel Denmark is acknowledged for providing the fiber.

\section{References}

1. B. M. Trabold, A. Abdolvand, T. G. Euser, A. M. Walser, and P. S. Russell, "Amplification of higher-order modes by stimulated Raman scattering in h2-filled hollow-core photonic crystal fiber," Opt. Lett. 38, 600-602 (2013).

2. S. Ramachandran, C. Smith, P. Kristensen, and P. Balling, "Nonlinear generation of broadband polarisation vortices," Opt. Express 18, 23,212-23,217 (2010).

3. R. Ryf and et al., "Mode-equalized distributed Raman amplification in 137-km few-mode fiber," ECOC p. Th.13.K.5 (2011).

4. S. Ramachandran, P. Kristensen, and M. F. Yan, "Generation and propagation of radially polarized beams in optical fibers," Opt. Lett. 34, 2525-2527 (2009).

5. J. Bromage, K. Rottwitt, and M. Lines, "A method to predict the Raman gain spectra of germanosilicate fibers with arbitrary index profiles," Photonics Technology Letters, IEEE 14, 24 -26 (2002). 